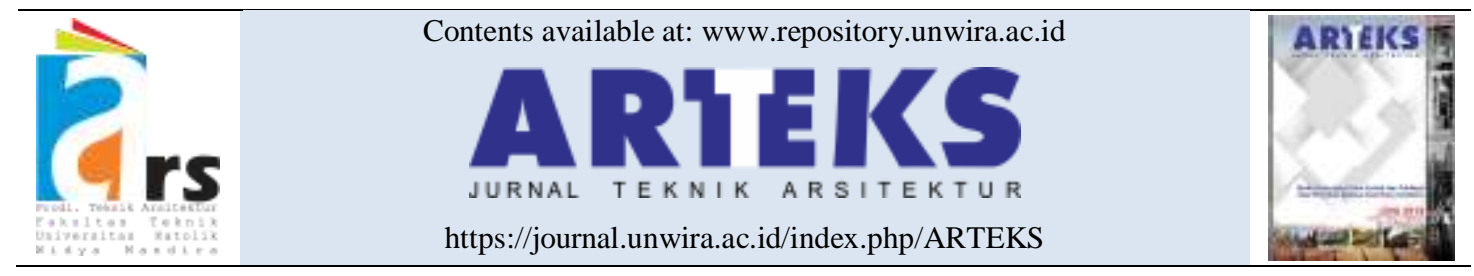

Research paper

doi: 10.30822/arteks.v6i3.1071

\title{
Effectiveness of adaptive façade with helicon mechanisms on energy values and natural lighting in Indonesia
}

\author{
Aldhi Nugraha Anantama, Agus Hariyadi \\ Department of Architecture and Planning, \\ Faculty of Engineering, Universitas Gadjah Mada \\ Jl. Grafika, No. 2, Sekip, Yogyakarta, Indonesia
}

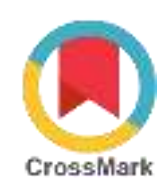

\begin{tabular}{|c|c|}
\hline ARTICLE INFO & ABSTRACT \\
\hline $\begin{array}{l}\text { Article history: } \\
\text { Received April 16, } 2021 \\
\text { Received in revised form June 14, } 2021 \\
\text { Accepted July 04, } 2021 \\
\text { Available online December 01, } 2021\end{array}$ & $\begin{array}{l}\text { The annual growth of energy consumption in both residential and } \\
\text { public buildings has been established globally as been significantly } \\
\text { increasing. Therefore, the proposed active and passive building } \\
\text { designs are intended to provide convenience and greatly reduce the } \\
\text { high energy requirements, before considering mechanical systems }\end{array}$ \\
\hline $\begin{array}{l}\text { *Corresponding author: Agus Hariyadi } \\
\text { Department of Architecture and planning, } \\
\text { Faculty of Engineering, Univesitas Gadjah } \\
\text { Mada, Indonesia } \\
\text { Email: agus@ @ ugm.ac.id } \\
\text { ORCID: https://orcid.org/0000-0003-3617- } \\
3790\end{array}$ & $\begin{array}{l}\text { (associated with fossil fuel-based energy consumption). This } \\
\text { encourages the development of a new design, such as the Climate } \\
\text { Adaptive Building Shell (CABS). This study aims to assess the } \\
\text { effectiveness of CABS with Helicone mechanisms on energy and } \\
\text { natural lighting, as well as its influential factors. The parametric } \\
\text { modeling simulation method was applied to compare the energy and } \\
\text { natural lighting aspects, between the adaptive and static facades of } \\
\text { the Helicone mechanism. The results indicated that the adaptive } \\
\text { facade was more effective than the static, based on energy and } \\
\text { natural lighting. It was also found that the } 30^{\circ} \text { adaptive } \\
\text { configuration with the Helicone mechanism was the most effective. } \\
\text { These results were influenced by several factors, i.e., the small } \\
\text { turning angle }\left(30^{\circ} \text { and } 150^{\circ}\left(-30^{\circ}\right) \text { and the anticlockwise direction }\right. \\
\text { of the adaptive facade rotation. }\end{array}$ \\
\hline
\end{tabular}

\section{Introduction}

Global energy consumption has been estimated to increase by $48 \%$ within 20 years $(2020-2040)$ (Mols and Blumberga 2020). In the 2010s, the building sector was found to dominate the global energy consumption with a percentage of $40 \%$, mostly used for HVAC (Heating, Ventilation, and Air-conditioning) purposes, since modern humans spend $90 \%$ of their time indoors (Soflaei et al. 2020; Natephra, Yabuki, and Fukuda 2018; Ricci et al. 2019). This growth leads to several problems, e.g., increased $\mathrm{CO}_{2}$ emissions, ozone depletion, climate change, greenhouse effect, and global warming (Hosseini et al. 2019; Jayathissa et al. 2017; Ricci et al. 2021; Seputra 2018).

The building envelope is calculated to contribute $40 \%$ more heat loss or overheating.
This does not keep up with changing outdoor conditions, and is exacerbated by the WWR (Window to Wall Ratio) configuration and inefficient opening orientation (Yan et al. 2019; Hariyadi et al. 2021). Therefore, the proposed active and passive building designs are intended to provide convenience and greatly reduce the high energy requirements, before considering mechanical systems (associated with fossil fuelbased energy consumption). Based on this condition, Loonen released the Climate Adaptive Building Shell (CABS) planning approach in 2013 (Loonen et al. 2013). This approach focuses on designing smart building envelopes, which adapts to both outdoor conditions and user 
requirements, in order to reduce HVAC energy consumption (Shahin 2019).

CABS has several variations as the intended physical linkage, e.g., thermal, optical, air, and electrical (Loonen et al. 2013). Based on its working system, CABS aims to effectively achieve several aspects (such as the physical linkage above), although these aspects compete with each other and also have opposite characteristics (Mols, Blumberga, and Karklina 2017). Conceptually, the approach was applied to several buildings 30 years ago, before being proclaimed by Loonen (Mols and Blumberga 2020).

CABS is still observed to be in the development and refinement stages until the preparation of this research (Mols and Blumberga 2020), which focuses on the performance of CABS as an adaptive facade, by applying the mechanism of Helicone. This mechanism was created by John Edmark in 2008, as a kinetic sculpture consisting of several stacked blades. Its kinetic system starts when the rotation of the top or bottom blade continuously trigger other rotators at a specific angle (Richman-Abdou 2018). Furthermore, this study uses the Helicone Mechanism for its mechanical properties, which allows the maximum possible changes in geometric configurations with minimal movement or energy use.
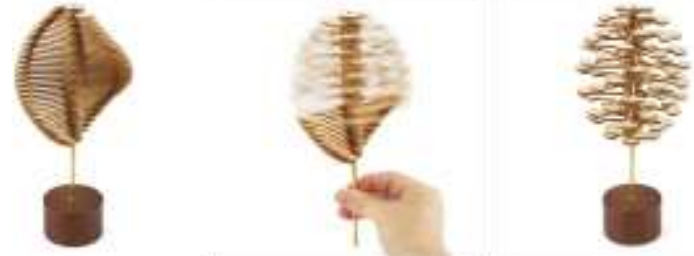

Figure 1. Helicone mechanism (Richman-Abdou 2018)

The problem of this research focuses on the effectiveness of adaptive facades with the Helicone mechanism, based on the energy values and natural lighting, as well as identifying its influential factors. This research is also expected to enrich references, regarding adaptive facade mechanisms and other related topics. Based on the limitations, this study only tested the OTTV value for the energy aspect, Illumination rate, and Glare for the lighting context.

\section{Method}

This study applied the Simulation Modeling method, by making a reality copy and representing the model operation. Modeling and simulation were performed using parametricbased software, i.e., Rhinoceros 5, Grasshopper 0.9, Ladybug 0.0.69, and Honeybee 0.0.66. These systems were used to facilitate simulations carried out on adaptive facades with various movement configurations. However, this condition differs from a static facade with one configuration (Kim and Clayton 2020).

\section{Test room model}

The first research object is a test room model with dimensions and properties, as shown in figure 1 and table 1 , respectively. This model represented a workspace in a building positioned on the ground floor, and was directly adjacent to another room on the roof and all walls, except those with aperture.

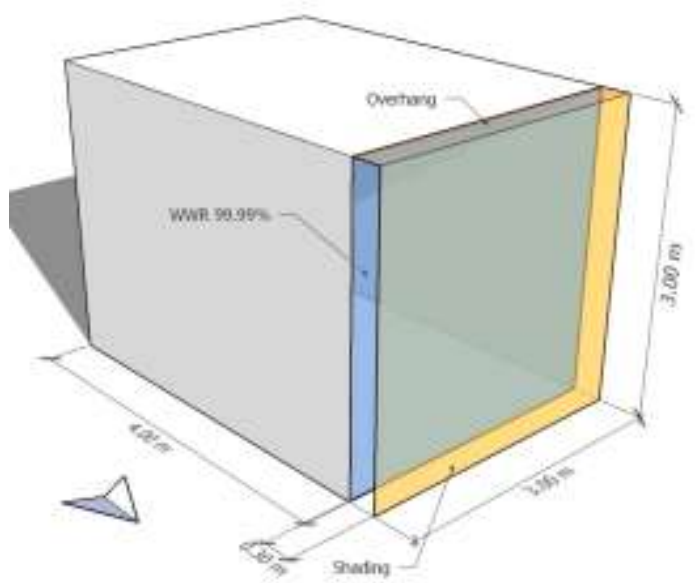

Figure 2. Test room model

Table 1. Simulation properties

\begin{tabular}{ll}
\hline EPW & Jakarta \\
\hline Glass SHGC & SHGC 0.7 \\
\hline Equipment load per area & $10 \mathrm{~W} / \mathrm{m}^{2}$ \\
\hline Lighting density per area & $3 \mathrm{~W} / \mathrm{m}^{2}$ \\
\hline People per area & $0.1 \mathrm{Pp} 1 / \mathrm{m}^{2}$ \\
\hline Ventilation per area & $0.000305 \mathrm{~m}^{3} / \mathrm{s}-\mathrm{m}^{2}$ \\
\hline Recirculated air per area & $0.00236 \mathrm{~m}^{3} / \mathrm{s}-\mathrm{m}^{2}$ \\
\hline
\end{tabular}

Adaptive facade model

This was modeled as having six square slats with a dimension of $0.5 \mathrm{~m}$ on each side, as the utilized Helicone mechanism started from a norotation condition (state 0). Furthermore, the full rotation started from the bottom to the top bar 
(state 6), as the movement scheme and application are presented in figure 2 and 3 , respectively.

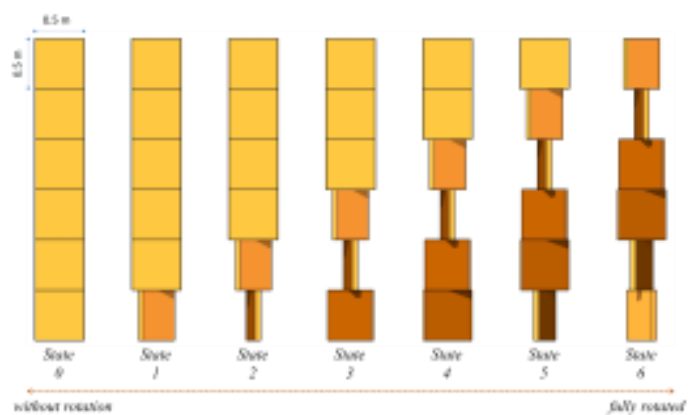

Figure 3. Adaptive facade movement scheme

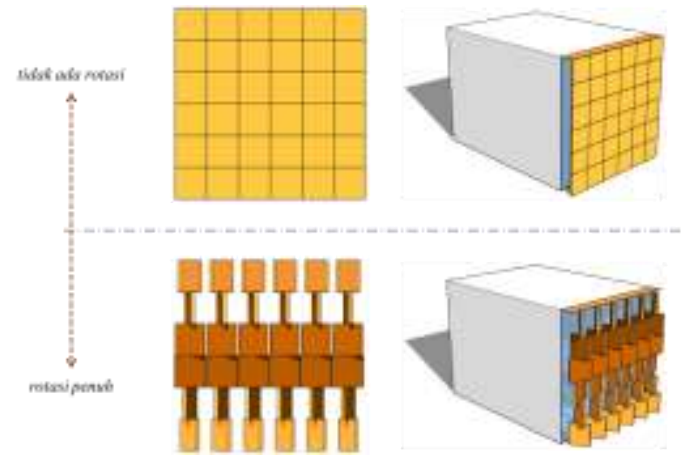

Figure 4. Adaptive facade implementation scheme

According to this study, the adaptive facade of the Helicone mechanism compared five configurations of trigger angles, namely $30^{\circ}, 60^{\circ}$, $90^{\circ}, 120^{\circ}$ (or $-60^{\circ}$ ), and $150^{\circ}$ (or $-30^{\circ}$ ). Based on this condition, the positive angle rotated anticlockwisely and vice versa. Each of these configurations represented the general angle characteristics as follows,

- $30^{\circ}$ and $150^{\circ}\left(-30^{\circ}\right)$ represented angles with small rotations in each Helicone state;

- $60^{\circ}$ and $120^{\circ}\left(-60^{\circ}\right)$ represented angles with large rotations in each Helicone state;

- $90^{\circ}$ as perpendicular angles in the helicone state.

These various characteristics also created variations in the adaptive facade openness, which was calculated from the void to solid ratio of each configuration. The schematic configuration and void/solid ratio is shown in figure 5 .

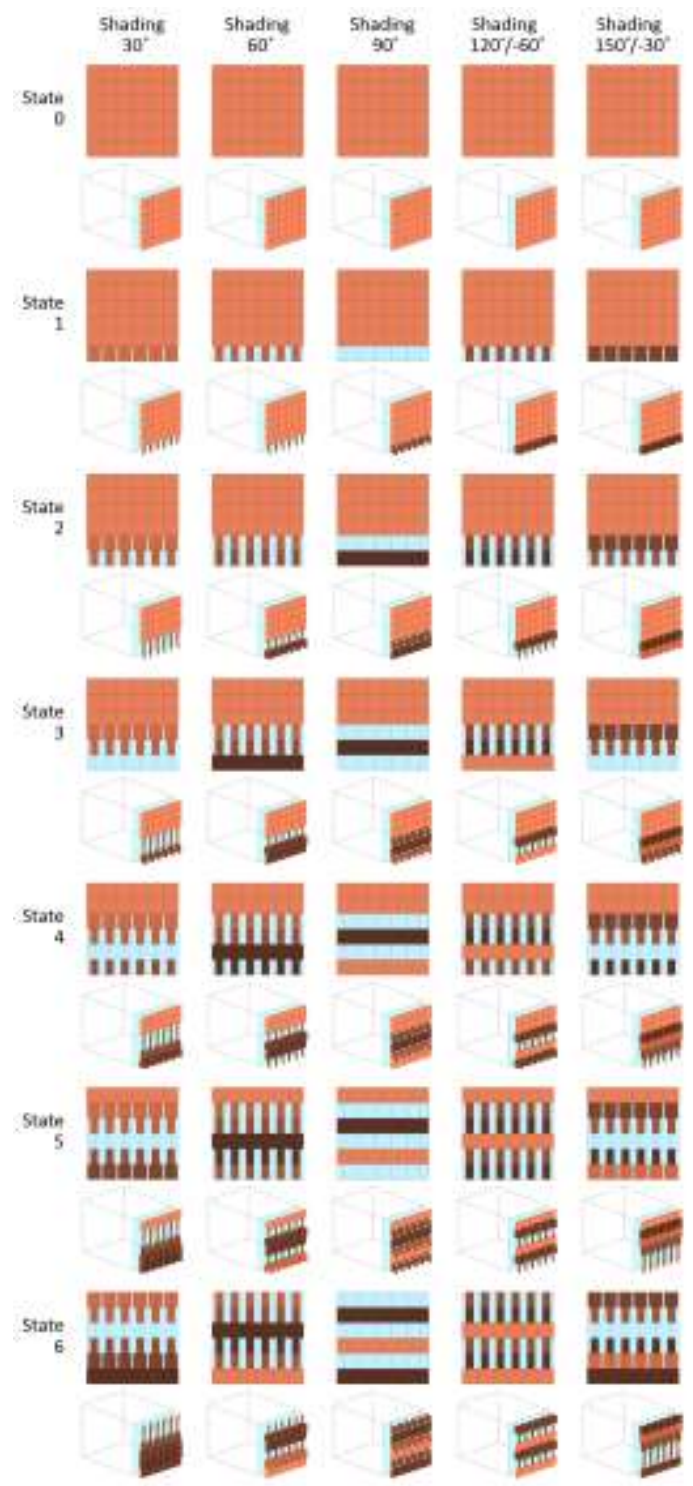

Figure 5. Front view schematic of adaptive facade configuration

Static facade model

The static facade in this study served as a comparison to the adaptive types, with angle configurations of $0^{\circ}, 45^{\circ},-45^{\circ}$, and $90^{\circ}$. This facade had parallel open blades and similar dimensions like the adaptive configuration, without the Helicone mechanism. Each configuration also represented a degree of openness, i.e., $0^{\circ}$ and $90^{\circ}$ fully closed and opened, as well as $45^{\circ}$ and $-45^{\circ}$ half-opened. The schematic is shown in figure 6. 


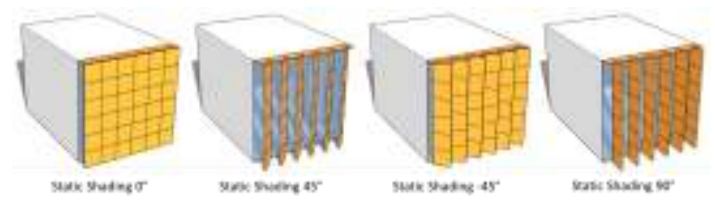

Figure 6. Static facade schematic

Simulation

Three form of analysis were carried out in this study, namely OTTV, Illuminance, and Glare simulations, respectively. The details of this analysis are as follows.

\section{a. OTTV Simulation}

This measures the average total value of heat transfer that passes through the building envelope per square metre, within a full year (Hwang et al. 2018). Based on this study, the standard OTTV value was below $35 \mathrm{~W} / \mathrm{m}^{2}$ according to $\mathrm{SNI}$ 6389:2011 (Hariyadi, Fukuda, and Ma 2017).

\section{b. Illumination simulation}

Based on a reference, the Illumination simulation used the UDI (Useful Daylight Illuminance) measurement scheme, and classified the value of natural light into several parts (Nabil and Mardaljevic 2006):

- $<100$ lux

: not significant,

- $100-500$ lux

: effective,

- $500-2000$ lux

: tolerable,

- > 2000 lux

: uncomfortable.

Illumination value was measured from five points in multiples of $0.4 \mathrm{~m}$ from the window, which is further referred to as the viewpoint. Each viewpoint was measured at an elevation of $0.8 \mathrm{~m}$, in order to simulate the general height of the workbench (Neufert 2002), as shown in figure 7.

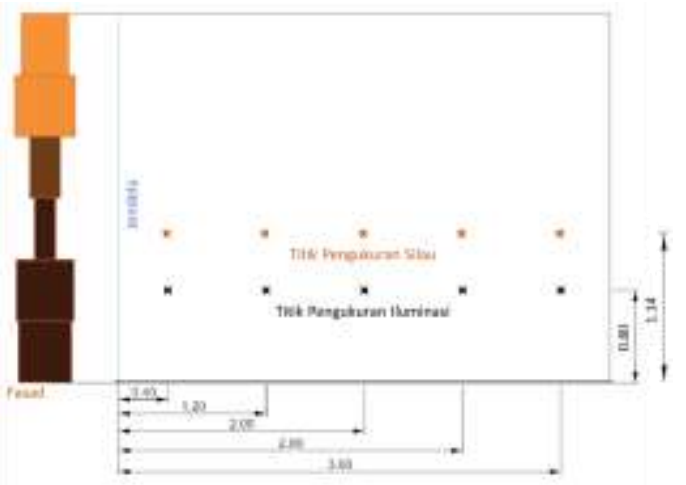

Figure 7. Viewpoint of illumination and glare simulation c. Glare simulation

Based on this study, the Glare simulation refers to the DGP (Daylight Glare Probability) benchmark, which is carried out by assessing the probability of being disturbed by natural light (Rizi and Eltaweel 2021; Yamín Garretón et al. 2021). Furthermore, DGP is classified as follows,

- DGP $<0.35 \quad$ : Imperceptible Glare,

- $0.35 \leqslant$ DGP < 0.4 : Perceptible Glare,

- $0.4 \leqslant$ DGP $<0.45$ : Disturbing Glare,

- DGP $\geqslant 0.45 \quad$ : Intolerable Glare.

Glare simulation was also measured from five viewpoints like Illumination, however, at an elevation of $1.17 \mathrm{~m}$. This elevation represented the human eye position when sitting, based on the results generated from the Grasshopper software. The schematic was also observed in figure 7 above.

\section{Simulation period}

In addition to the OTTV simulations that should be calculated for a whole year, Illumination and Glare analysis were carried out during an extreme three-month period, by referring to the research of Tabadkani et al. (2019), as well as Bahdad, Fadzil, and Taib (2020). Additionally, the time was in accordance with the working/office hours in Indonesia, as shown in table 2 below.

Table 2. Simulation period

\begin{tabular}{lll}
\hline Month & Date & Hour \\
\hline March & $1-31$ & $8: 00-17: 00$ \\
\hline June & $1-30$ & $8: 00-17: 00$ \\
\hline December & $1-31$ & $8: 00-17: 00$ \\
\hline
\end{tabular}

\section{Result and discussion}

Based on determining the effectiveness of adaptive facade, each aspect of the OTTV, Illumination, and Glare simulation values were compared with that of various static facade configurations as follow,

\section{OTTV simulation}

The simulations carried out produced the OTTV value for the adaptive facade, as shown in figure 8. Based on meeting the SNI, this value was only realized at state 0 for all types of adaptive configurations, with a high rate of $34 \mathrm{kWh} / \mathrm{m}^{2}$.

According to the graphic pattern, facade configurations with small rotations, such as $30^{\circ}$ and $150^{\circ}\left(-30^{\circ}\right)$, have the advantage of lower 
OTTV values in the initial state (states 1 and 2). Meanwhile, large rotation configurations such as $60^{\circ}$ and $120^{\circ}\left(-60^{\circ}\right)$, produced lower values in the final states (states 4,5 , and 6 ). Based on its peak in state 6 , the highest OTTV value was found at $63 \mathrm{kWh} / \mathrm{m}^{2}$, which was produced from a $90^{\circ}$ adaptive configuration. It also showed that the $90^{\circ}$ rotation produced the most unstable value between states.

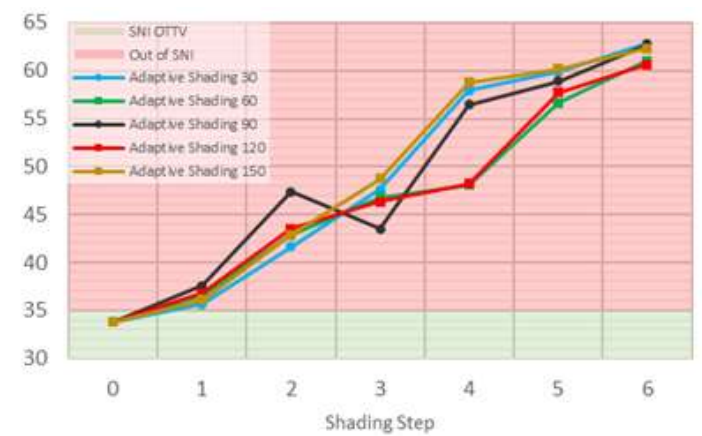

Figure 8. Results of adaptive facade OTTV simulation

These pattern variations were due to the differences in the void/solid openness ratio in each adaptive configuration with a helicone mechanism. The configuration with a small rotation also produced a small ratio at the beginning, which steadily increased in each state, until it attained maximum value at the final level. This differed from a large rotation $/ 90^{\circ}$ with a void/solid ratio, which was larger in the beginning, and increased or stabilized in the following states. Furthermore, the configuration had a lower ratio than the facade with small rotation in the final state. This caused low OTTV values and instability in the final level, as shown in the $90^{\circ}$ configuration.

Based on the comparison to the OTTV rate of the static facade in figure 9, the adaptive configuration had advantages both in terms of range and maximum value. This value was often lower than the static facade, which almost attained $80 \mathrm{kWh} / \mathrm{m}^{2}$ on the $90^{\circ}$ rotation. Therefore, the adaptive facade was $20 \%$ more effective than the static configuration in its maximum openness conditions. It was also equipped with various states that met the needs and desires of the user. In addition to these differences, adaptive and static facades also had similarities, i.e., positive rotation configurations (e.g., $30^{\circ}$ and $45^{\circ}$ adaptive and static facades) often produced lower OTTV values than the negative types (e.g., $150^{\circ}\left(-30^{\circ}\right)$ and $-45^{\circ}$ adaptive and static facades).

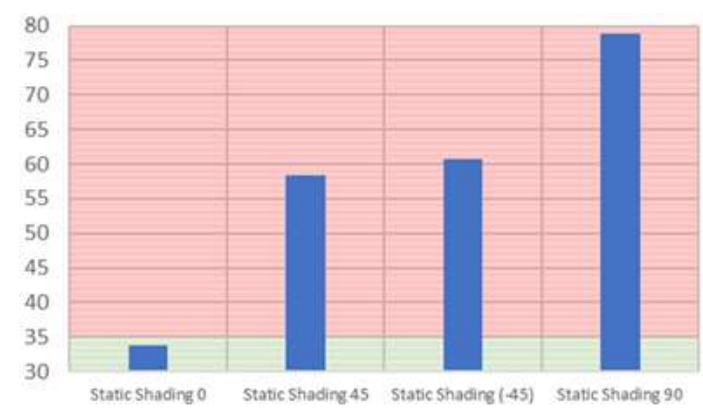

Figure 9. Results of static facade OTTV simulation

\section{Illumination simulation}

The results of the Illumination were totally and strongly influenced by the monthly trajectory of the sun, as exemplified by the adaptive configuration of $30^{\circ}$ in figure 10 . This data showed the highest illumination value in June, when the sun's trajectory was directly in front of the test room aperture. It was also followed by the trajectory that was above and backing away from the test room in March and December, respectively. Furthermore, similar result was obtained from the illumination simulation of the static facade in figure 11. However, the adaptive configuration obtained lower rates $(25 \%)$ than the static facades, based on the range and maximum values. It affirmed that adaptive facades produced more effective illumination values than the static configurations. This was also coupled with the adjusted state variance, based on demands.

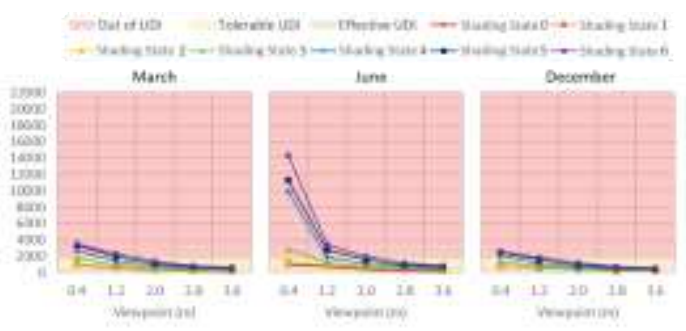

Figure 10. Illumination simulation results of $30^{\circ}$ adaptive facade

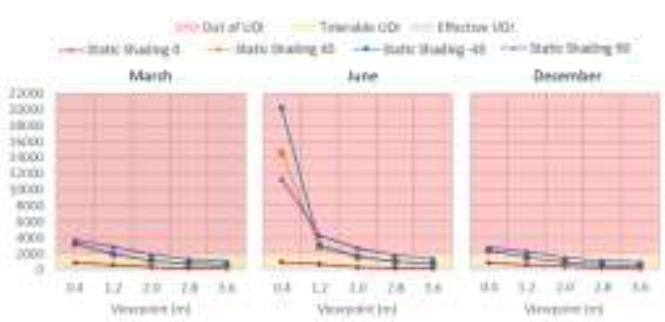

Figure 11. Static facade illumination simulation results 
Based on determining the best adaptive facade in theilllumination simulation, all data were compared in two tables. Table 3 contained a collection of data from the average illumination value of each facade configuration, state, and monthly viewpoint. The green data also showed the facade configuration that produced the lowest value, compared to others. Therefore, it was concluded that the $30^{\circ}$ and $60^{\circ}$ configurations dominantly generated the lowest Illumination values in the initial and final states, respectively.

Furthermore, table 4 showed a collection of data from the standard UDI illumination values (100 lux - 2000 lux), during the simulation period. This was equipped with a green bar that represented the value of each data, which further indicated that the higher the percentage of the bar length, the better the configuration. Table 4 also showed a similar pattern to the previous illustration (table 3), where the best optimization was dominated by a $30^{\circ}$ and $60^{\circ}$ adaptive and static configuration, for both the initial and final states, respectively. Additionally, the illumination optimization decreased at the viewpoints of 2.8 and $3.6 \mathrm{~m}$. This was due to the far distance from the aperture, which produced an illumination value that had not attained the minimum UDI standard (100 lux), under specific conditions.

According to this section, it was concluded that the positive rotational adaptive configurations $\left(30^{\circ}\right.$ and $\left.60^{\circ}\right)$ were the best in the illumination simulation.

Table 3. Average recapitulation of adaptive facade illumination

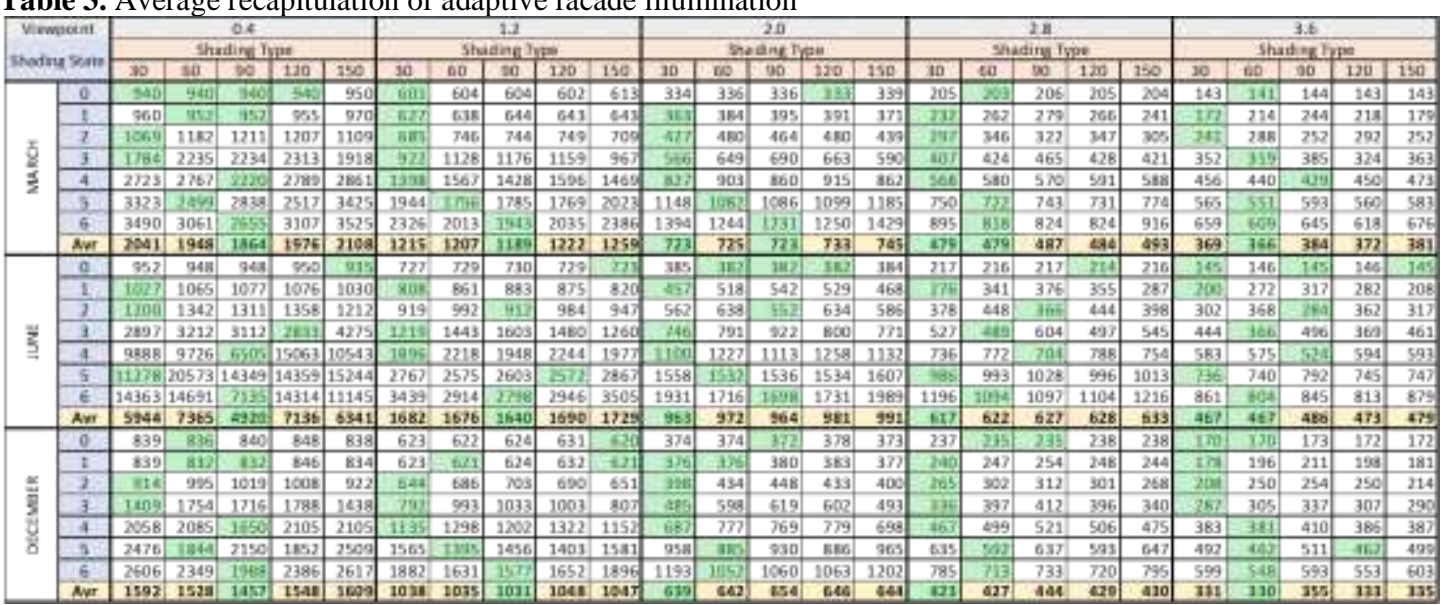

Table 4. Optimization recapitulation of adaptive facade illumination

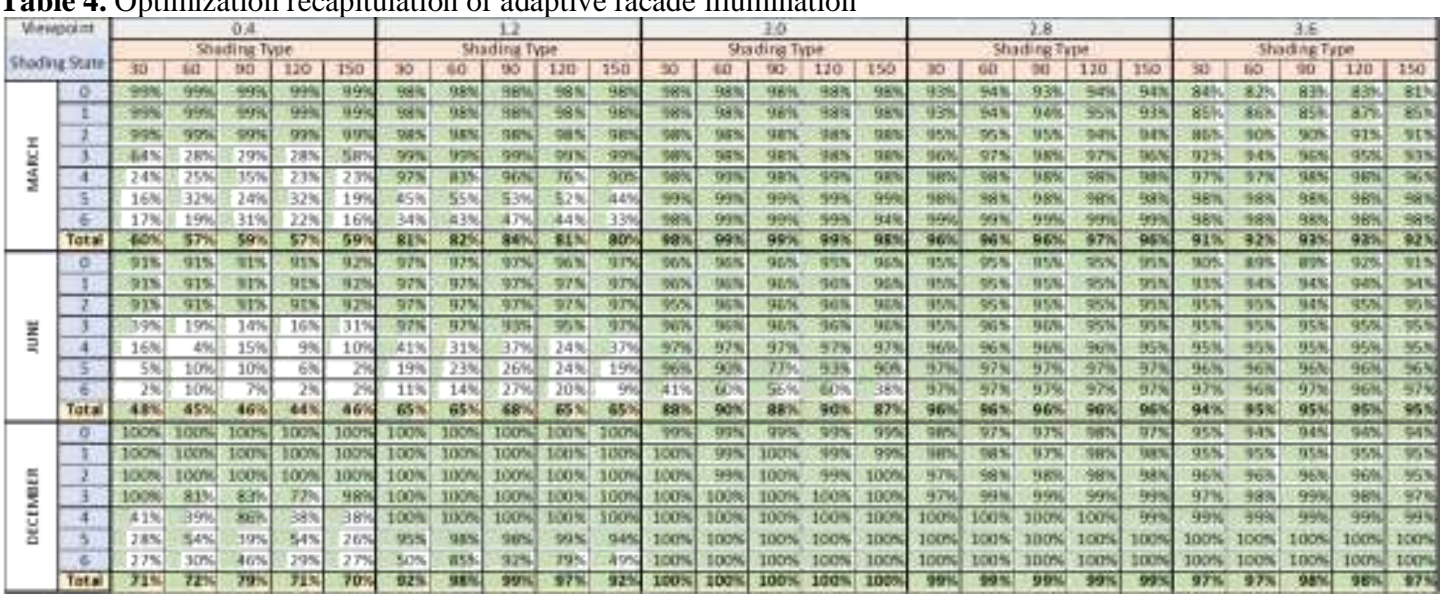

\section{Glare simulation}

According to this simulation, the total results had similar pattern as the Illumination, i.e., the highest glare values were in June, accompanied by March and December. Furthermore, the comparison was exemplified by the configuration of the $30^{\circ}$ adaptive facade (figure 12) with the static (figure 13). These results showed that 
adaptive configurations had a maximum glare value of $6 \%$, which was lower than the static facades. This indicated that the adaptive glare value was more effective than the static facade. The diversity of adaptive facade was also adjusted based on needs and/or demands.

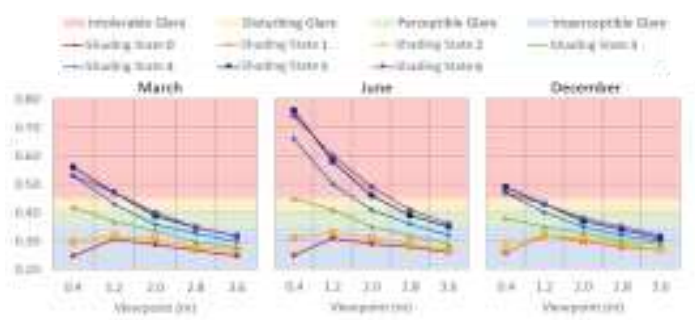

Figure 12. $30^{\circ}$ adaptive facade glare Simulation results

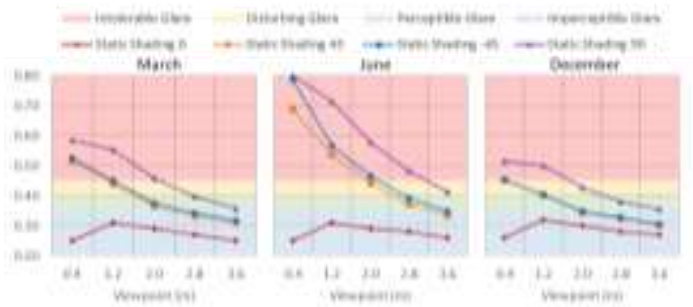

Figure 13. Static facade glare simulation results
Culture in settlement

Based on this simulation, a comparison to determine the best adaptive configuration was carried out.

Firstly, the average recapitulation in table 5 showed that the initial state of the lowest value was dominated by adaptive facade configurations with small rotations, i.e., $30^{\circ}$ and $150^{\circ}\left(-30^{\circ}\right)$. Meanwhile, the final state was dominated by large rotation configurations, such as $60^{\circ}$ and $120^{\circ}$ ($60^{\circ}$ ). Generally, configurations with constant positive rotation $\left(30^{\circ}\right.$ and $\left.60^{\circ}\right)$ were slightly superior to the negative types $\left(150^{\circ}\left(-30^{\circ}\right)\right.$ and $\left.120^{\circ}\left(-60^{\circ}\right)\right)$.

Secondly, a similar pattern was found in table 6 , based on comparison optimization. The percentages of the initial and final states were also dominated by small and large rotation configurations $\left(30^{\circ} / 150^{\circ}\right.$ and $\left.60^{\circ} / 120^{\circ}\right)$, respectively. Also, it was often outperformed by the facade with positive rotation $\left(30^{\circ}\right.$ and $\left.60^{\circ}\right)$.

Although the Glare simulation was influenced by rotational direction, it was also affected by the magnitude of the opening rotation in the configuration, which affected the void/solid ratio.

Table 5. Recapitulation of average adaptive facade glare

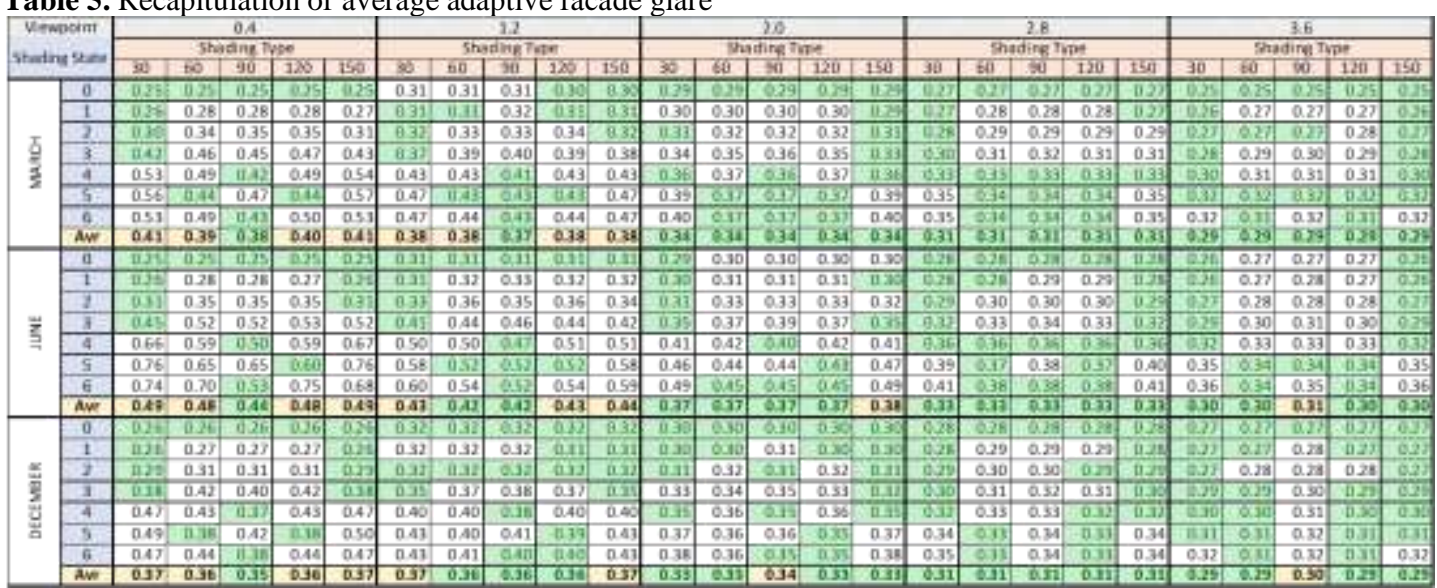

Table 6. Recapitulation of adaptive facade glare optimization

The most effective adaptive facade configuration with helicone mechanism

Based on this study, the most effective adaptive facade with the Helicone mechanism was the $30^{\circ}$ configuration. This configuration produced the lowest value at the initial states, based on the OTTV simulation. It also continued to constantly increase, and produced higher OTTV values than several adaptive configurations in the final states. This indicated a good trait for adaptive facades. According to the illumination and glare simulations, the $30^{\circ}$ adaptive configuration also dominated the lowest average values. Furthermore, it had the highest illumination and glare optimization values in the initial states. Although followed by a $60^{\circ}$ facade in the final states, the $30^{\circ}$ configuration was considered the most effective. Generally, the ideal 
condition for an adaptive facade was to produce the lowest possible value to the initial states. However, it still produced the maximum possible value to the final level, which had a significant effect between the states.

Effectiveness factors of adaptive facades with helicone mechanism

The simulations and analysis carried out in this study indicated several factors that affected the effectiveness of adaptive facades with the Helicone mechanism, as follow,

1. Trigger Angle

The trigger angle affected the geometry configuration and void/solid ratio of the adaptive facade with the Helicone mechanism. As previously noted, the $30^{\circ}$ adaptive configuration was the most effective, due to producing a low simulation value in the initial states, which steadily increased in the final levels. Furthermore, the small size of the trigger angles $\left(30^{\circ}\right.$ and $150^{\circ}$ $\left(-30^{\circ}\right)$ ) allowed the Helicone mechanism to produce a constant increase in the void/solid ratio of its states, compared to larger ones $\left(60^{\circ}, 120^{\circ}\right.$ ($60^{\circ}$ ), and $90^{\circ}$ ). The wide-angle also increased the unstable ratio, and produced an unbalanced graph of simulation values between states. Therefore, it was necessary to consider the measure of the trigger angle, and its relationship to the number of Helicone panels. This aimed to avoid repeated panel rotation, and obtain a constant void/solid ratio. Additionally, it also aimed to produce a stable simulation value between states, such as a small trigger angle, i.e., $30^{\circ}$ and $150^{\circ}\left(-30^{\circ}\right)$.

\section{Rotation Direction}

The direction of rotation also affected the effectiveness of the adaptive facade with the Helicone mechanism, although it was not as significant as the first factor. Based on the assessment from all the simulations performed, the adaptive configuration of $30^{\circ}$ with a anticlockwise rotation often obtained a more effective value than $150^{\circ}\left(-30^{\circ}\right)$ with clockwise movement. The direction also affected the panel opening direction of the adaptive facade. Furthermore, the $30^{\circ}$ and $-30^{\circ}$ rotations anticlockwisely and clockwisely caused the panel to open towards the East and West, respectively. Therefore, further research was needed on the 'direction of rotation' factor, as this simulation was only limited to openings in the North orientation.

\section{Conclusion}

Based on this study, adaptive facades with the Helicone mechanism were more effective than static configurations. This produced lower values of $20 \%, 25 \%$, and $6 \%$ in the OTTV, Illumination, and Glare simulations, respectively. The study also obtained an adaptive configuration that produced the most effective value in all aspects of the simulation, i.e., a facade (adaptive) with a trigger angle of $30^{\circ}$. This configuration was superior to others, based on producing the highest value of optimization in meeting comfort standards, especially natural lighting. It also had a pattern of low simulation values in the initial states, and steadily increased until the final levels, which was an ideal condition for an adaptive facade.

The simulation analysis further formulated the factors that affected the effectiveness of the adaptive configuration with Helicone mechanism, i.e., the size of the angle and rotational direction. This angle was closely related to the ratio of openness or void/solid adaptive facade. Furthermore, this configuration with small trigger angles $\left(30^{\circ}\right.$ and $\left.150^{\circ}\left(-30^{\circ}\right)\right)$ produced a constant $\mathrm{void} / \mathrm{solid}$ ratio between the states. It allowed stable simulation value that was ideal as an adaptive facade, when compared to configurations with large angles $\left(60^{\circ}, 120^{\circ}\left(-60^{\circ}\right)\right.$, and $90^{\circ}$ ). The rotational direction factor also affected the effectiveness of the adaptive facade. Based on this study, the adaptive configuration with anticlockwise rotation $\left(30^{\circ}\right)$ was dominant in producing lower OTTV, Illumination, and Glare simulation values. It was also more effective than facades with clockwise rotation $\left(-30^{\circ}\right)$. This was assumed because the anticlockwise and clockwise configurations caused the adaptive facade panels to open to the East and West, respectively.

\section{References}

Bahdad, Ali Ahmed Salem, Sharifah Fairuz Syed Fadzil, and Nooriati Taib. 2020. 'Optimization of Daylight Performance Based on Controllable Light-Shelf Parameters Using Genetic Algorithms in the Tropical Climate of Malaysia'. Journal of Daylighting 7 (1): 122 36. https://doi.org/10.15627/jd.2020.10.

Hariyadi, Agus, Hiroatsu Fukuda, and Qingsong Ma. 2017. 'The Effectiveness of the 
Parametric Design "Sudare" Blind as External Shading for Energy Efficiency and Visibility Quality in Jakarta'. Architectural Engineering and Design Management 13 (5): 384-403. https://doi.org/10.1080/17452007.2017.1296 811.

Hariyadi, Agus, Esti Setyaning Jati, Nabila Afif, and Alya Farah Taufiqoh. 2021. 'The Comparison of Device Materials of Sliding Sudare Using a Prototyping Method'. ARTEKS : Jurnal Teknik Arsitektur 6 (1): 45 54. https://doi.org/10.30822/arteks.v6i1.569.

Hosseini, Seyed Morteza, Masi Mohammadi, Alexander Rosemann, Torsten Schröder, and Jos Lichtenberg. 2019. 'A Morphological Approach for Kinetic Façade Design Process to Improve Visual and Thermal Comfort: Review'. Building and Environment 153 (April): $\quad$ 186-204. https://doi.org/10.1016/j.buildenv.2019.02.04 0 .

Hwang, Ruey-Lung, Wen-Mei Shih, Tzu-Ping Lin, and Kuo-Tsang Huang. 2018. 'Simplification and Adjustment of the Energy Consumption Indices of Office Building Envelopes in Response to Climate Change'. Applied Energy 230 (November): 460-70. https://doi.org/10.1016/j.apenergy.2018.08.0 90.

Jayathissa, P., J. Zarb, M. Luzzatto, J. Hofer, and A. Schlueter. 2017. 'Sensitivity of Building Properties and Use Types for the Application of Adaptive Photovoltaic Shading Systems'. Energy Procedia 122 (September): 139-44. https://doi.org/10.1016/j.egypro.2017.07.319.

Kim, Hyoungsub, and Mark J. Clayton. 2020. 'A Multi-Objective Optimization Approach for Climate-Adaptive Building Envelope Design Using Parametric Behavior Maps'. Building and Environment 185 (November): 107292. https://doi.org/10.1016/j.buildenv.2020.1072 92.

Loonen, R.C.G.M., M. Trčka, D. Cóstola, and J.L.M. Hensen. 2013. 'Climate Adaptive Building Shells: State-of-the-Art and Future Challenges'. Renewable and Sustainable Energy Reviews 25 (September): 483-93. https://doi.org/10.1016/j.rser.2013.04.016.

Mols, Toms, and Andra Blumberga. 2020. 'Inverse Modelling of Climate Adaptive Building Shells. System Dynamics Approach'. Environmental and Climate
Technologies $24 \quad$ (2): $170-77$. https://doi.org/10.2478/rtuect-2020-0064.

Mols, Toms, Andra Blumberga, and Ieva Karklina. 2017. 'Evaluation of Climate Adaptive Building Shells: Multi-Criteria Analysis'. Energy Procedia 128 (September): 292-96.

https://doi.org/10.1016/j.egypro.2017.09.077.

Nabil, Azza, and John Mardaljevic. 2006. 'Useful Daylight Illuminances: A Replacement for Daylight Factors'. Energy and Buildings 38 (7): 905-13. https://doi.org/10.1016/j.enbuild.2006.03.013

Natephra, Worawan, Nobuyoshi Yabuki, and Tomohiro Fukuda. 2018. 'Optimizing the Evaluation of Building Envelope Design for Thermal Performance Using a BIM-Based Overall Thermal Transfer Value Calculation'. Building and Environment 136 (May): 12845.

https://doi.org/10.1016/j.buildenv.2018.03.03 2.

Neufert, Ernest. 2002. Data Arsitek. 33rd ed. Jakarta: Erlangga.

Ricci, Adele, Caterina Ponzio, Kristian Fabbri, Jacopo Gaspari, and Emanuele Naboni. 2021. 'Development of a Self-Sufficient Dynamic Façade within the Context of Climate Change'. Architectural Science Review 64 (12): 87-97. https://doi.org/10.1080/00038628.2020.1713 042.

Ricci, Adele, Caterina Ponzio, Jacopo Gaspari, and Emanuele Naboni. 2019. 'A Study on the Impact of Climate Adaptive Building Shells on Indoor Comfort'. Journal of Facade Design and Engineering 7 (1). https://doi.org/https://doi.org/10.7480/jfde.20 19.1.2778.

Richman-Abdou, Kelly. 2018. 'Kinetic Toy Transforms From a Pinecone to a Helix with the Simple Flick of a Wrist'. My Modern Met. 2018. https://mymodernmet.com/johnedmark-helicone/.

Rizi, Rana Abdollahi, and Ahmad Eltaweel. 2021. 'A User Detective Adaptive Facade towards Improving Visual and Thermal Comfort'. Journal of Building Engineering 33 (January): 101554. https://doi.org/10.1016/j.jobe.2020.101554.

Seputra, Jackobus Ade Prasetya. 2018. 'Numeric Analysis of Air Distribution in AirConditioned Room to Obtain Optimum 
Energy Effeciency Level'. ARTEKS : Jurnal Teknik Arsitektur 3 (1): 45-56. https://doi.org/10.30822/arteks.v3i1.53.

Shahin, Hadeer Samir Mohamed. 2019. ‘Adaptive Building Envelopes of Multistory Buildings as an Example of High Performance Building Skins'. Alexandria Engineering Journal 58 (1):

$345-52$ https://doi.org/10.1016/j.aej.2018.11.013.

Soflaei, Farzaneh, Mehdi Shokouhian, Amir Tabadkani, Hamed Moslehi, and Umberto Berardi. 2020. 'A Simulation-Based Model for Courtyard Housing Design Based on Adaptive Thermal Comfort'. Journal of Building Engineering 31 (September): 101335 . https://doi.org/10.1016/j.jobe.2020.101335.

Tabadkani, Amir, Masoud Valinejad Shoubi, Farzaneh Soflaei, and Saeed Banihashemi. 2019. 'Integrated Parametric Design of Adaptive Facades for User's Visual Comfort'. Automation in Construction 106 (October): 102857.

https://doi.org/10.1016/j.autcon.2019.102857

Yamín Garretón, Julieta, Ayelén María Villalba, Roberto Germán Rodriguez, and Andrea
Pattini. 2021. 'Roller Blinds Characterization Assessing Discomfort Glare, View Outside and Useful Daylight Illuminance with the Sun in the Field of View'. Solar Energy 213 (January):

91-101. https://doi.org/10.1016/j.solener.2020.11.027.

Yan, Shuai, Xianting Li, Baolong Wang, Wenxing Shi, and Weihua Lyu. 2019. 'A Method to Describe the Thermal Property of Pipe-Embedded Double-Skin Façade: Equivalent Glass Window'. Energy and Buildings 195 (July): 33-44. https://doi.org/10.1016/j.enbuild.2019.04.041

\section{Author(s) contribution}

Aldhi Nugraha Anantama contributed to the research concepts preparation, methodologies, investigations, data analysis, visualization, articles drafting and revisions.

Agus Hariyadi contribute to the research concepts preparation and literature reviews, data analysis, of article drafts preparation and validation. 